\title{
Diterpene biosynthesis by the dinoflagellate symbiont of the Caribbean gorgonian Pseudopterogorgia bipinnata
}

\author{
Jennifer M. Boehnlein, Lory Z. Santiago-Vázquez, Russell G. Kerr* \\ Center of Excellence in Biomedical and Marine Biotechnology, Florida Atlantic University, 777 Glades Road, Boca Raton, \\ Florida 33431, USA
}

\begin{abstract}
Chemical analysis of the dinoflagellate symbiont of Pseudopterogorgia bipinnata (Verrill) revealed higher concentrations of kallolides and related diterpenes than are present in the intact holobiont. Further, biosynthetic studies of the dinoflagellate with ${ }^{3} \mathrm{H}$-labeled geranylgeranyl diphosphate indicated that this alga is capable of kallolide biosynthesis. These data indicate that the symbiotic zooxanthellae of $P$. bipinnata, as we have previously shown with $P$. elisabethae, are capable of biosynthesizing diterpenes previously ascribed solely to the host coral. Analyses of $P$. bipinnata colonies indicate significant chemical variation within this species, and 4 distinct chemotypes have been identified. Of these, only Chemotype A was found to both contain diterpenes and be capable of diterpene biosynthesis. We analyzed small subunit rDNA restriction fragment length polymorphism patterns and internal transcribed spacer sequences of the zooxanthellae associated with the 4 chemotypes for genetic differences that could explain the chemical differences. Both studies determined that all chemotypes are predominantly populated by the symbiont Symbiodinium sp. Clade B.
\end{abstract}

KEY WORDS: Zooxanthellae $\cdot$ Terpene $\cdot$ Kallolide $\cdot$ Symbiodinium sp. $\cdot$ Restriction fragment length polymorphism $\cdot$ Natural product $\cdot$ Biosynthesis

Resale or republication not permitted without written consent of the publisher

\section{INTRODUCTION}

Many soft-coral species in the Caribbean form close associations with dinoflagellates of the genus Symbiodinium. Nutrition, in the form of translocated photosynthates, is the primary contribution of the dinoflagellates (Muscatine \& Porter 1977). In turn, the coral host provides inorganic nutrients (Schmitz \& Kremer 1977) as well as physical protection (Goiran et al. 1997). This close mutualistic association between coral host and algal symbiont (zooxanthellae) has been the subject of much research in recent years due, in part, to episodes of coral bleaching that threaten the health of this delicate and diverse ecosystem. Several studies have revealed correlations between the genetic identity of a given symbiont and the host-coral species with which it associates. In some cases, a given coral species will only host a specific strain of zooxanthellae (Santos et al. 2004), while other coral hosts are not so discriminating (Rowan \& Knowlton 1995, Toller et al. 2001).
The nuclear ribosomal RNA (rDNA) gene complex is a tandem repeat unit from 1 to several thousand copies with several domains evolving at varying rates (Jorgesen \& Cluster 1988, Cullings \& Vogler 1998) that has been used to explore genetic diversity within the genus Symbiodinium. Within this unit, the $18 \mathrm{~S}$ and $28 \mathrm{~S}$ rDNA evolve relatively slowly and can be used to define broad phylogenetic relatedness (Maidak et al. 1997). Restriction fragment length polymorphism (RFLP) analysis of the small subunit of ribosomal DNA (ssu rDNA) can further classify members of the genus Symbiodinium to the cladal level, designated A, B, C, D, E, and F, which probably comprises of many different species (Rowan \& Powers 1991a, Baker \& Rowan 1997, Rowan 1998, Pawlowski et al. 2001). To determine inter- and intraspecific relationships, examination of the rapidly evolving internal transcribed spacer (ITS) region can be performed.

There has been debate in the literature as to the biosynthetic origins of diterpenes in corals that harbor 
symbiotic dinoflagellates (Papastephanou \& Anderson 1982, Kokke et al. 1984, Ciereszko 1989, MichalekWagner et al. 2001), and to date no broad generalizations can be definitively made. In a previous publication (Mydlarz et al. 2003), we presented data that implicates the algal symbiont of Pseudopterogorgia elisabethae as a biosynthetic source of the pseudopterosins; potent anti-inflammatory agents that have an existing market as a cosmetic additive. The purified symbiont from $P$. elisabethae was shown to have a high concentration of the pseudopterosins as well as biosynthetic intermediates. Also, various biosynthetic experiments with labeled metabolites demonstrated that these microalgae contain the biosynthetic machinery for pseudopterosin production. In one experiment, isolated Symbiodinium sp. cells were incubated with $\mathrm{NaH}^{14} \mathrm{CO}_{3}$. Algal cells that were maintained in a dark/ light cycle produced ${ }^{14} \mathrm{C}$-labeled pseudopterosins while cells that were maintained in the dark did not. Secondly, a cell-free extract of isolated algae was capable of transforming ${ }^{3} \mathrm{H}$-geranylgeranyl diphosphate (GGDP) to the pseudopterosins.

In an effort to extend our studies, and determine if dinoflagellate production of diterpenes is a widespread phenomenon within this genus, we have examined the diterpene content, biosynthetic capabilities, and the genetic identities of the algal symbiont(s) of Pseudopterogorgia bipinnata. This Caribbean octocoral is known to produce diterpenes of the pseudopterane and cembrane families (Rodriguez et al. 1999).

\section{MATERIALS AND METHODS}

General chromatographic procedures. Thin layer chromatography (TLC) analysis was performed using precoated silica gel $\mathrm{UV}_{254}$ plates (Whatman) with a mobile phase of hexanes/EtOAc (60:40). Spots were visualized by spraying the plate with $10 \% \mathrm{H}_{2} \mathrm{SO}_{4}$ in $\mathrm{MeOH}$ and charring on a hot plate or in an oven. Davisil Grade 633 Type 60A 200 to 425 mesh (Fisher) silica gel was used with hexanes and EtOAc for normalphase column chromatography. Normal-phase HPLC purification was performed using a Vydac semipreparative column and a mobile-phase gradient from $100 \%$ hexanes to hexanes/EtOAc (50:50) with UV detection at $270 \mathrm{~nm}$. Reverse-phase HPLC was performed using a semi-preparative Phenomenex phenylhexyl column and a mobile-phase gradient of $\mathrm{MeOH} /$ $\mathrm{H}_{2} \mathrm{O}(50: 50)$ to $\mathrm{MeOH}(100 \%)$ with UV detection at $270 \mathrm{~nm} .{ }^{1} \mathrm{H}-\mathrm{NMR}$ (nuclear magnetic resonance) spectra were recorded at $500 \mathrm{MHz}$ in $\mathrm{CDCl}_{3}$ or $\mathrm{C}_{6} \mathrm{D}_{6}$ on a Varian Innova spectrometer.

Coral material. Pseudopterogorgia bipinnata was collected at Sweetings Cay, Bahamas in May of 2002 by SCUBA diving at a depth of $10 \mathrm{~m}$. The corals were dried in the sun and grouped by TLC fingerprint into Chemotypes A to D (see Fig. 1). Corals being used for biosynthetic work were kept alive in buckets of seawater until TLC analysis was completed. The individual chemotypes were then flash-frozen in liquid nitrogen and kept at $-80^{\circ} \mathrm{C}$ until needed. Additional collections were obtained from the Florida Keys and Lee Stocking Island, Exuma, Bahamas. Comparison of both gross colony morphology and spicules with the published descriptions indicated that all 4 chemotypes represented P. bipinnata (Verrill) (Bayer 1961).

Zooxanthellae isolation. Coral tissue $(300 \mathrm{~g}$ frozen weight) was homogenized in a Waring blender using 11 deionized water. The resulting slurry was divided into $50 \mathrm{ml}$ Falcon tubes and centrifuged at $350 \times g$ for $5 \mathrm{~min}$. The supernatant was decanted and the pellet resuspended in deionized water. This was repeated until the supernatant was clear. The pellet was resuspended, layered over $100 \%$ Percoll, and centrifuged at $38 \times g$ to pellet spicules. The zooxanthellae formed a brown band above the Percoll, which was transferred to another Falcon tube using a plastic pipette. This cell layer was diluted with deionized water and layered over a discontinuous gradient of 30, 70 and $100 \%$ Percoll and centrifuged at $350 \times g$ for $30 \mathrm{~min}$. The layer of cells was cleaned 3 additional times in the same manner until no further debris was observed under a light microscope. The cells were then frozen with liquid nitrogen and lyophilized to dryness.

Zooxanthellae used in biosynthetic studies were isolated in the same manner, then resuspended in a sodium phosphate buffer $(100 \mathrm{mM})$ containing $3 \mathrm{mM}$ EDTA. These were frozen with liquid nitrogen and kept at $-80^{\circ} \mathrm{C}$ until needed.

Extraction and purification of diterpenes. Dried coral specimens of each chemotype were extracted in $\mathrm{MeOH} / \mathrm{CH}_{2} \mathrm{Cl}_{2}$ (1:1), and extracts evaporated to dryness under vacuum. The resulting gums were dissolved in $\mathrm{MeOH} / \mathrm{H}_{2} \mathrm{O}$ (9:1) and partitioned with hexanes. The aqueous partitions were then adjusted to $\mathrm{MeOH} / \mathrm{H}_{2} \mathrm{O}$ (1:1), and partitioned a second time with $\mathrm{CH}_{2} \mathrm{Cl}_{2}$. The organic extracts were redissolved in $\mathrm{CH}_{2} \mathrm{Cl}_{2}$ and dried onto silica gel under vacuum. The dried extracts were layered on top of a silica gel column and eluted using a step gradient from $100 \%$ hexanes to $100 \%$ EtOAc to afford 6 fractions (A to F). These fractions were subjected to normal and reversed-phase HPLC to purify Diterpenes 1 to 3.

Incubation of purified zooxanthellae with $\left[\mathrm{C}_{1}{ }^{3} \mathrm{H}\right]$ geranylgeranyl diphosphate. Purified zooxanthellae in $100 \mathrm{mM}$ phosphate buffer with $3 \mathrm{mM}$ EDTA were thawed in ice water. Magnesium chloride ( $5 \mathrm{mM}$ ) and 2-mercaptoethanol $(5 \mathrm{mM})$ were added to the thawed cell suspension. The zooxanthellae were then incu- 
bated with $2 \mu \mathrm{Ci}$ of ${ }^{3} \mathrm{H}$-GGDP (50 to $60 \mathrm{Ci} \mathrm{mmol}{ }^{-1}$ ) at $29^{\circ} \mathrm{C}$ and $200 \mathrm{rpm}$ on an environmental shaker for $24 \mathrm{~h}$. The incubation was quenched by freezing in liquid nitrogen and the cells were lyophilized to dryness. Kallolide A was purified from this incubation mixture in the same manner as that used for the coral holobiont.

Catalytic hydrogenation/hydrogenolysis of Kallolide A. Kallolide A $(0.01931 \mathrm{mmol})$ was dissolved in $5 \mathrm{ml}$ EtOAc and transferred to a flask containing 3\% Pd-activated charcoal and a stir bar. The flask was purged of air and filled with hydrogen 3 times. The reaction solution was allowed to stir at ambient temperature for $20 \mathrm{~h}$, and then filtered through Celite. The reduced product was purified using reverse-phase HPLC with $3 \% \mathrm{H}_{2} \mathrm{O}$ in $\mathrm{MeOH}$ as the mobile phase.

DNA isolation. DNA extractions were conducted using the DNeasy Plant Miniprep Kit (Qiagen) following the manufacturer's protocol. The isolated DNA was quantified and assessed for purity by measuring the absorbance at 260 and $280 \mathrm{~nm}$ and calculating the A260:A280 ratio. The DNA was aliquoted at $50 \mathrm{ng}^{-1} \mathrm{l}^{-1}$ and stored at $-80^{\circ} \mathrm{C}$ until needed.

Amplification of ssu rDNA. The small subunit of ribosomal genomic DNA (ssu rDNA) was PCR amplified using the universal primer ss5 (5'-GGT TGA TCC TGC CAG TAG TCA TAT GCT TG-3') with the zooxanthellae specific primer ss3Z (5'-AGC ACT GCG TCA GTC CGA ATA ATT CAC CGG-3') according to established procedures (Rowan \& Powers 1991a,b). In general, $1 \mu \mathrm{l}$ of DNA (50 $\mathrm{ng} \mathrm{\mu l}^{-1}$ ) was used in a $50 \mu \mathrm{l}$ PCR reaction containing $0.5 \mu \mathrm{l}$ Taq (2.5 U; Qiagen), $5 \mu \mathrm{l}$ $10 \times$ buffer, $3 \mu \mathrm{l} 25 \mathrm{mM} \mathrm{MgCl}_{2}, 1 \mu \mathrm{l} 100 \mathrm{mM}$ dNTPs, $1 \mu \mathrm{l}$ $10 \mathrm{mM}$ ss5, and $1 \mu \mathrm{l} 10 \mathrm{mM}$ ss $3 Z$. PCR cycling conditions were an initial denaturing period of $3 \mathrm{~min}$ at $92^{\circ} \mathrm{C}$ followed by 30 cycles of $92^{\circ} \mathrm{C}$ for $30 \mathrm{~s}, 52^{\circ} \mathrm{C}$ for $40 \mathrm{~s}$, and $72^{\circ} \mathrm{C}$ for $30 \mathrm{~s}$. A final extension of 5 min at $72^{\circ} \mathrm{C}$ was added, and 5 to $10 \%$ of the reaction was loaded on a $1.2 \%$ agarose gel $(0.6 \%$ Metaphor agarose $/ 0.6 \%$ Seakem agarose; Fisher Scientific), ran at $110 \mathrm{~V}$, and visualized by ethidium bromide. The expected PCR amplicon was $\sim 1650 \mathrm{bp}$.

Restriction fragment length polymorphism (RFLP) analysis of ssu rDNA. Samples of the 4 Pseudopterogorgia bipinnata chemotypes were analyzed for cladal identity by RFLP analysis of the ssu rDNA following the procedures described by LaJeunesse \& Trench (2000). In general, amplified products were digested with 1 to $5 \mathrm{U} \mathrm{TaqI}$ (Fisher Scientific) at $65^{\circ} \mathrm{C}$ for $3.5 \mathrm{~h}$ or with 1 to $5 \mathrm{U} D p n I I$ (New England BioLabs) at $37^{\circ} \mathrm{C}$ for $4.5 \mathrm{~h}$. Samples were loaded on a $2.5 \%$ agarose gel, ran at $70 \mathrm{~V}$ for $3 \mathrm{~h}$, and visualized by ethidium bromide.

ITS amplification. The internal transcribed spacer region (ITS-rDNA) was PCR-amplified using the zooxanthellae-specific primers ZITSUPM13 (5'-CAC GAC GTT GTA AAA CGA CCC GGT GAA TTA TTC GGA
CTG ACG CAG TGC T-3') and ZITSDNM13 (5'-GGA TAA CAA TTT CAC ACA GGC TGT TTA GTT CCT TTT CCT CCG C-3') designed to amplify between the conserved regions of the $3^{\prime}$ and $5^{\prime}$ ends of the zooxanthellae 18S and 28S rDNA genes (Santos et al. 2001). PCR reactions were prepared as described in subsection 'Amplification of ssu rDNA'. PCR cycling conditions were an initial denaturing period of $2 \mathrm{~min}$ at $94^{\circ} \mathrm{C}$ followed by 30 cycles of $94^{\circ} \mathrm{C}$ for $40 \mathrm{~s}, 53^{\circ} \mathrm{C}$ for $1 \mathrm{~min}$, and $72^{\circ} \mathrm{C}$ for $1 \mathrm{~min}$. A final extension of $30 \mathrm{~min}$ at $72^{\circ} \mathrm{C}$ was added. Gel electrophoresis was performed as explained in subsection 'Amplification of ssu rDNA'. The expected PCR amplicon was $\sim 750 \mathrm{bp}$.

Sequence analysis of ITS-rDNA region. The ITS PCR amplicon was gel-purified using a Minelute gel extraction kit (Qiagen), and concentrated by SpeedVac. The purified fragments were sent to the University of Florida DNA Sequencing Facility (Department of Biological Sciences, Tallahassee, Florida). The ribosomal ITS-rDNA region was sequenced using primers composed of the first 19- and 20-5'nucleotides of ZITSUPM13 and ZITSDNM13, respectively (Santos et al. 2001) using Big Dye Terminator Version 3.1 Cycle Sequencing Kit (Applied Biosystems). Sequences were viewed in Chromas (Technelysium), edited in EditSeq, and aligned using the Clustal W Method in Megalign (Lasergene 6.0, DNASTAR). Sequences were also submitted and blasted at the NCBI database (available at: www.ncbi.nlm.nih.gov). Accession numbers are AY894809 for Chemotype A, AY894810 for Chemotype B, AY894811 for Chemotype C and AY894812 for Chemotype D.

\section{RESULTS}

\section{Chemical studies}

\section{Pseudopterogorgia bipinnata from Sweetings Cay,} Bahamas

Analysis of Pseudopterogorgia bipinnata colonies by TLC revealed 4 distinct patterns which we labeled A to D (Fig. 1). While there was a noticeable variation in the color of the gorgonians, there was no correlation of color with TLC pattern. The relative abundance of each chemotype at Sweetings Cay (10 m depth), for a sample size of 30 colonies, was $28 \%$ Type A, $48 \%$ Type B, $22 \%$ Type C and $2 \%$ Type D. No physical differences were observed between color morphs or chemotypes, and representative specimens of each chemotype were identified as $P$. bipinnata (Verrill) based on gross colony morphology and by spicule analysis following the method of Bayer (1961). Since the observed TLC patterns are the result of compounds of both ani- 


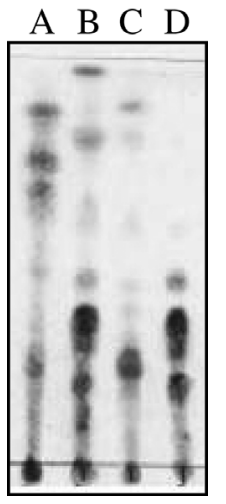

Fig 1. Pseudopterogorgia bipinnata. Normal-phase TLC of Chemotypes A to D

mal and algal origin, we decided to examine the contributions of both holobiont and isolated symbiont.

Chemical analysis of the methylene chloride extract from Chemotype A holobiont yielded the known compounds Kallolide A (1), Kallolide A acetate (2), and 2O-methylbipinnatin J (3) (Fig. 2). Their identity was confirmed by comparing ${ }^{1} \mathrm{H}$-NMR spectra to those reported in the literature (Look et al. 1986). Due to the fact that the algal symbionts are localized within the gastrodermal tissue of the coral host, it is not possible to reliably isolate coral tissue that is free of zooxanthellae. This factor impeded our ability to analyze the coral host tissue in the samples. However, the dinoflagellate symbiont can be readily isolated by homogenizing the coral tissue and using gradient centrifugation to separate the zooxanthellae from the coral tissue fragments (Mydlarz et al. 2003). This method was used to obtain a preparation of the dinoflagellate symbiont of Pseudopterogorgia bipinnata. Table 1 summarizes the relative amounts of Kallolides 1 and 2 and Bipinnatin 3 in the holobiont and purified algal symbiont.

Interestingly, no diterpenes were detected in Chemotypes $\mathrm{B}, \mathrm{C}$ or D despite repeated examination of the holobionts and their associated zooxanthellae. Solventpartitioning, column chromatography, and normal and

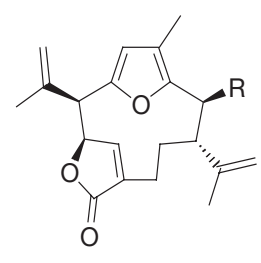

kallolide $\mathrm{A}(\mathbf{1}) \mathrm{R}=\mathrm{OH}$ kallolide $\mathrm{A}$ acetate $(\mathbf{2}) \mathrm{R}=\mathrm{OAC}$

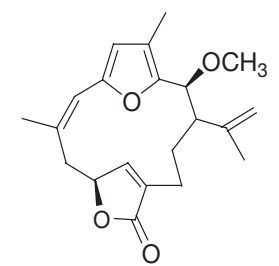

2-O-methyl bipinnatin $\mathrm{J}(3)$

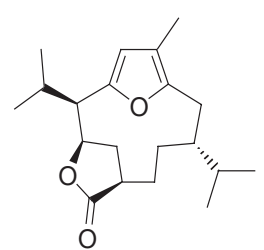

hexahydro derivative (4)
Fig. 2. Pseudopterogorgia bipinnata. Diterpenes Kallolide A (1), Kallolide A acetate (2) and 2-O-methylbipinnatin (3) present in Chemotype A holobiont; and hexahydro derivative (4) used to confirm radiochemical purity reversed-phase HPLC were used to fractionate the $\mathrm{CH}_{2} \mathrm{Cl}_{2}$ extract. None of the fractions obtained showed evidence of diterpenes by NMR analysis. We suspect that some of the compounds evident on TLC are oxidized sterols. We also used GC-MS to search for diterpene cyclase products in the non-polar extracts of Chemotypes B to D. We were able to identify cembrene $\mathrm{A}$ in the hexane extract of Chemotype A by GCMS and by NMR. However, analysis of the hexanes fraction from Chemotypes B, C, and D for diterpene cyclase products $\left(\mathrm{M}^{+} 272\right)$ using GC-MS failed to detect any such compounds.

\section{Pseudopterogorgia bipinnata from Florida Keys and Lee Stocking Island, Bahamas}

Collections of Pseudopterogorgia bipinnata from the Florida Keys (15 to $30 \mathrm{~m}$ depths) exhibited the same chemotypic diversity as those from Sweetings Cay, but the relative abundances were slightly different: $47 \%$ Type A, 21\% Type B, 23\% Type C, and 9\% Type D. Interestingly, a collection from Lee Stocking Island, Bahamas at $34 \mathrm{~m}$ was exclusively Type $\mathrm{D}$, while another collection at the same reef, but at $17 \mathrm{~m}$, was exclusively Type A. Collections were comprised of approximately 30 organisms from each site.

In a recent collection from the Florida Keys, we obtained specimens of Pseudopterogorgia bipinnata that were spawning in an area that we had demonstrated to contain all 4 chemotypes. Interestingly, upon TLC analysis, it was noted that the entire collection of spawning colonies was exclusively Type A.

\section{Biosynthetic studies of Symbiodinium sp. from Pseudopterogorgia bipinnata}

The biosynthetic capability of the isolated zooxanthellae was assessed by testing for the conversion of radiolabeled GGDP to kallolide A. Scintillation counting was used to quantify the conversion of the tritium-labeled GGDP to Kallolide A, which showed a specific activity of $1.07 \times 10^{5} \mathrm{dpm} \mathrm{mmol}^{-1}$. Following the methodology of Look et al. (1986), to confirm radiochemical purity we

Table 1. Comparison of diterpene content (\% dry weight of organism) of holobiont and zooxanthellae (Symbiodinium sp.) isolated from Pseudopterogorgia bipinnata

\begin{tabular}{|lcc|}
\hline Diterpene & Holobiont & Zooxanthellae \\
\hline Kallolide A & 0.07 & 1.7 \\
Kallolide A acetate & 0.30 & 3.9 \\
2-O-methyl bipinnatin J & 0.07 & 0.50 \\
\hline
\end{tabular}


performed a catalytic hydrogenation/ hydrogenolysis of the radiolabeled Kallolide A to obtain the hexahydro derivative (4) (Fig. 2) whose ${ }^{1} \mathrm{H}-\mathrm{NMR}$ was identical to that reported in the literature. The HPLC-purified derivative was found to have the same specific activity $\left(1.19 \times 10^{5} \mathrm{dpm} \mathrm{mmol}{ }^{-1}\right)$ as Kallolide A.

\section{Genetic studies of Symbiodinium sp. from Pseudopterogorgia bipinnata}

We were intrigued by the possibility that the gorgonian Pseudopterogorgia bipinnata could harbor different strains of Symbiodinium, thus explaining the differences observed in the chemistry of the 4 chemotypes. To explore this possibility, RFLP analysis was performed on the ssu DNA isolated from symbionts from each chemotype of holobiont. Following the methods developed by Rowan \& Powers (1991b) and by LaJeunesse \& Trench (2000), symbionts from all chemotypes were shown to be predominantly members of Clade B from the RFLP pattern for TaqI (Fig. 3). The pattern for DpnII also showed a preponderance of Clade B Symbiodinium for all 4 chemotypes, and faint bands for what appear to be Clade A.

Genetic sequence analysis of the ITS region of the 4 groups of symbionts confirmed the predominance of Clade B Symbiodinium in all 4 chemotypes. This was determined using a BLAST search of the NCBI database. ITS sequences were between 99.3 to $99.9 \%$ identical between the 4 chemotypes (Table 2). When the 4 chemotypes were compared to Symbiodinium of Clades A, C or E, the percent identity was significantly less.

Table 2. Symbiodinium sp. Percent identity of ITS sequences of Symbiodinium populations of Pseudopterogorgia bipinnata Chemotypes A, B, C and D (PBA, PBB, PBC, PBD) using Clustal W method for sequence alignment. Accession Nos.: Clade A, AF427467; Clade C, AF427469; Clade E, AF396629

\begin{tabular}{|c|c|c|c|c|c|c|c|}
\hline & \multicolumn{7}{|c|}{ — Percent identity (\%) } \\
\hline & PBA & PBB & $\mathrm{PBC}$ & PBD & Clade A & Clade C & Clade E \\
\hline PBA & - & 99.4 & 99.6 & 99.6 & 62.2 & 75.8 & 68.8 \\
\hline PBB & 0.4 & - & 99.9 & 99.4 & 62.0 & 75.3 & 68.6 \\
\hline PBC & 0.3 & 0.1 & - & 99.3 & 61.9 & 75.5 & 68.7 \\
\hline PBD & 0.4 & 0.6 & 0.7 & - & 62.1 & 75.5 & 68.4 \\
\hline Clade A & 44.2 & 44.6 & 44.9 & 44.2 & - & 68.5 & 67.9 \\
\hline Clade C & 28.6 & 29.3 & 29.0 & 28.8 & 40.5 & - & 71.2 \\
\hline Clade E & 38.0 & 38.3 & 38.0 & 38.5 & 41.1 & 34.2 & - \\
\hline
\end{tabular}

\section{DISCUSSION}

As was the case in our examination of Pseudopterogorgia elisabethae (Mydlarz et al. 2003), the zooxanthellae from $P$. bipinnata had a significantly higher concentration of diterpenes than the holobiont. This observation suggests that the symbiont is producing these compounds. It is, however, conceivable that the diterpenes are produced elsewhere and the zooxanthellae are merely sites in which they are stored. To test the hypothesis that the dinoflagellate symbiont of $P$. bipinnata is indeed a biosynthetic producer of the diterpenes, experiments were carried out with radiolabeled GGDP, the ubiquitous diterpene precursor. The recovered Kallolide A (1) was radioactive, and derivatization to Compound 4 and comparison of the specific activity of this derivative with that of the recovered Kallolide A demonstrated that 1 was radiochemically pure. The derivatization reaction used in this experiment efficiently produces a compound with significantly differing mobility with both normal and reversed-phase HPLC, thus allowing for a high level of confidence in assessing radiochemical purity. Based on the results of these experiments, we conclude that the kallolide family of diterpenes is not only localized, but is also produced within the algal symbiont of $P$. bipinnata Chemotype A. 
Unlike Pseudopterogorgia elisabethae, $P$. bipinnata from a given site can be further classified into 4 distinct chemotypes based on chemical fingerprints. The fact that only symbionts from Chemotype A produce diterpenes, along with the holobiont's apparent temporal reproductive isolation, may indicate that it is in fact a different species in spite of its physical similarity to Chemotypes B, C, and D. This could explain why seemingly identical hosts associate with dramatically different (chemically) symbionts.

The genetic analysis of the Symbiodinium sp. from the 4 chemotypes is intriguing, as this does not readily explain the observed chemical differences. From the data, it can be concluded that the predominant Symbiodinium sp. population for all 4 Pseudopterogorgia bipinnata chemotypes is Clade $\mathrm{B}$, with the possibility of a cryptic population of Clade A throughout. However, a more detailed analysis using such identifiers as microsatellites may reveal differences in Symbiodinium populations. It can be hypothesized that subspecies-level genetic differences between the zooxanthellae, not detectable by the methodologies used in this study, are responsible for the differences in secondary metabolite production.

The data reported in this manuscript, along with our previously published results indicating that the dinoflagellate symbiont of Pseudopterogorgia elisabethae is capable of pseudopterosin biosynthesis (Mydlarz et al. 2003), suggests that in gorgonians of the genus Pseudopterogorgia, diterpene biosynthesis does occur within the symbiotic zooxanthellae. Efforts are currently underway to further define the extent of this phenomenon in other gorgonians of the Caribbean region. The question remains as to whether or not diterpene production within this genus is exclusively the domain of the symbiont, or if the host coral contributes in some manner. Examination of the coral host itself hinges on the ability to isolate pure host-coral tissue, which we have so far been unable to obtain. Additional, finer scale molecular studies are also necessary to clarify the genetic identity and relatedness between those symbionts that are capable of diterpene biosynthesis and those that are not.

Acknowledgements. We acknowledge funding from the Center of Excellence in Biomedical and Marine Biotechnology at Florida Atlantic University. L.Z.S.-V. was funded as a minority postdoctoral fellow by the National Science Foundation. We gratefully acknowledge R. Ritson-Williams, Smithsonian Marine Station at Fort Pierce, for his assistance with the taxonomic identification. We also thank the Florida Institute of Oceanography and the crew of the RV 'Bellows' for the granting of ship time, and the staff at the Keys Marine Laboratory, as well as the Perry Institute for Marine Science and the staff at Lee Stocking Island for their invaluable assistance with fieldwork. Many thanks also to the Government of the Bahamas for granting us permission to undertake these stud- ies within their territorial waters. This is Contribution no. P200521 from the Center of Excellence.

\section{LITERATURE CITED}

Baker AC, Rowan R (1997) Diversity of symbiotic dinoflagellates (zooxanthellae) in scleratinian corals of the Caribbean and eastern Pacific. Proc 8th Int Coral Reef Symp 2: 1295-1300

Bayer FM (1961) The shallow water octocorallia of the West Indian region, a manual for marine biologists. Martinus Nijhoff, The Hague

Ciereszko LS (1989) Sterol and diterpenoid production by zooxanthellae in coral reefs: a review. Biol Oceanogr 6: 363-374

Cullings KW, Vogler DR (1998) A 5.8S nuclear ribosomal RNA gene sequence database: applications to ecology and evolution. Mol Ecol 7:919-923

Goiran C, Allemand D, Galgani I (1997) Transient Na+ stress in symbiotic dinoflagellates after isolation from coral-host cells and subsequent immersion in seawater. Mar Biol 129: $581-589$

Jorgesen RD, Cluster PD (1988) Modes and tempos in the evolution of nuclear ribosomal DNA: new characters for evolutionary studies and new markers for genetic and population studies. Ann Mo Bot Gard 75:1238-1247

Kokke WCMC, Epstein S, Look SA, Rau GH, Fenical W, Djerrasi C (1984) On the origin of terpenes in symbiotic associations between marine invertebrates and algae (zooxanthellae). J Biol Chem 259:8168-8173

LaJeunesse TC, Trench RK (2000) Biogeography of two species of Symbiodinium (Freudenthal) inhabiting the intertidal sea anemone Anthopleura elegantissima (Brandt). Biol Bull (Woods Hole) 199:126-134

Look S, Fenical W, Matsumoto G, Clardy J (1986) The pseudopterosins: a new class of anti-inflammatory and analgesic diterpene pentosides from the marine sea whip Pseudopterogorgia elisabethae. J Org Chem 51: 5140-5145

Maidak BL, Olsen GL, Larsen N, Overbeck R, McCaughey MJ, Woese CR (1997) The RPD (Ribosomal Database Project). Nucleic Acids Res 25:109-110

Michalek-Wagner K, Bourne DJ, Bowden BF (2001) The effects of different strains of zooxanthellae on the secondary-metabolite chemistry and development of the softcoral host Lobophytum compactum. Mar Biol 138:753-760

Muscatine L, Porter JW (1977) Reef corals: mutualistic symbiosis adapted to nutrient poor environments. BioScience $27: 454-60$

Mydlarz LD, Jacobs RS, Boehnlein J, Kerr RG (2003) Pseudopterosin biosynthesis in Symbiodinium sp., the dinoflagellate symbiont of Pseudopterogorgia elisabethae. Chem Biol 10:1-20

Papastephanou C, Anderson DG (1982) Crassin acetate biosynthesis in a cell-free homogenate of zooxanthellae from Pseudoplexaura porosa (Houttyun): Implications to the symbiotic process. Comp Biochem Physiol 73B: 617-624

Pawlowski J, Holzman M, Hahrni JF, Pochon X, Lee JJ (2001) Molecular identification of algal symbionts in large miliolid foraminifera: 2. Dinoflagellates. J Eukaryot Microbiol 48:368-373

Rodriguez AD, Shi JG, Huang S (1999) Highly oxygenated pseudopterane and cembranolide diterpenes from the Caribbean sea feather Pseudopterogorgia bipinnata. J Nat Prod (Lloydia) 62:1228-1237 
Rowan R (1998) Diversity and ecology of zooxanthellae on coral reefs. J Phycol 34:407-417

Rowan R, Knowlton N (1995) Intraspecific diversity and ecological zonation in coral-algal symbiosis. Proc Natl Acad Sci USA 92:2850-2853

Rowan R, Powers DA (1991a) A molecular genetic classification of zooxanthellae and the evolution of animal-algal symbioses. Science 251(4999):1348-1351

Rowan R, Powers DA (1991b) Molecular genetic identification of symbiotic dinoflagellates (zooxanthellae). Mar Ecol Prog Ser 71:65-73

Santos SR, Taylor DJ, Coffroth MA (2001) Genetic comparison of freshly isolated versus cultured symbiotic dinoflagel-

Editorial responsibility: Joseph Pawlik (Contributing Editor), Wilmington, North Carolina, USA lates: implications for extrapolating to the intact symbiosis. J Phycol 37:900-912

Santos SR, Shearer L, Hannes R, Coffroth MA (2004) Finescale diversity and specificity in the most prevalent lineage of symbiotic dinoflagellates (Symbiodinium, Dynophyceae) of the Caribbean. Mol Ecol 13:459-469

Schmitz K, Kremer BP (1977) Carbon fixation and analysis of assimilates in a coral-dinoflagellate symbiosis. Mar Biol 42:305-313

Toller WW, Rowan R, Knowlton N (2001) Zooxanthellae of the Montastrea annularis complex: patterns of distribution of four taxa of Symbiodinium on different reefs and across depths. Biol Bull (Woods Hole) 201:348-359

Submitted: February 11, 2005; Accepted: May 25, 2005

Proofs received from author(s): November 8, 2005 